\title{
Prevalence of Salmonella in raw animal products in Ethiopia: a meta-analysis
}

\author{
Getachew Tadesse ${ }^{1 *}$ and Endrias Zewdu Gebremedhin ${ }^{2}$
}

\begin{abstract}
Background: The contributions of animal products to human salmonellosis differ across countries, and source attribution is a major step in prioritizing control measures. The objectives of this study were to estimate the prevalence of Salmonella in raw animal products in Ethiopia by using meta-analytical methods.

Results: The odds of Salmonella contaminated meat was more than twice higher in markets than in slaughter houses [Odds ratio $(\mathrm{OR})=2.25(95 \%$ Confidence Interval $[\mathrm{Cl}]=1.75,2.89)]$. The source species significantly affected meat contamination in slaughter houses $(P<0.05)$ but not in the markets $(P>0.05)$. The pooled estimates of Salmonella contaminated goat carcasses, beef carcasses, minced beef and milk were 3.86\%, 4.53\%, 8.34\% and $10.76 \%$ respectively.

Conclusions: The estimates demonstrate the extent of contamination, and imply the need for safety intervention measures to reduce the risks of contamination of animal products and human illnesses.
\end{abstract}

Keywords: Animal products, Ethiopia, Markets, Salmonella, Slaughter houses

\section{Background}

Salmonella is one of the major public health concerns all over the world. Whilst typhoidal infections are common in the tropics and subtropics where the sewage disposal system and the food handling hygienic standards are inadequate [1], non-typhoidal Salmonella (NTS) is important in both developed and developing countries. NTS enters the food chain at any point in livestock feed, and in food manufacturing, processing, retailing, catering and preparation [2]; survives typical catering refrigeration temperatures and increases in number under conditions of thermal abuse [3]. Apart from sporadic infections, outbreaks associated with the consumption of contaminated animal products have been recorded in several countries [4-9].

As the relative contributions of animal products to human salmonellosis differ across countries [10], source attribution is a major step in prioritizing control measures [11]. Elsewhere, different methods that included microbial sub-typing, comparative exposures, epidemiological analyses of sporadic cases and outbreaks, and expert elicitations have been used to attribute sources to human cases [10]. In Ethiopia, the incidence of food-borne salmonellosis

\footnotetext{
* Correspondence: getadesse1@yahoo.com

${ }^{1}$ Department of Biomedical Sciences, College of Veterinary Medicine and Agriculture, Addis Ababa University, P.O. Box 34, Debre Zeit, Ethiopia

Full list of author information is available at the end of the article
}

is unknown; the risk factors associated with the contamination of animal products are not described, and there have not been studies on attribution of sources to human illnesses. However, the considerable occurrence of carrier food animals ( $7.07 \%$ in cattle to $43.81 \%$ in pigs) [12] and the wide spread raw animal product consumption habit in a noteworthy segment of the population are suggestive of the risk of acquiring Salmonella from animal products. Therefore, quantitative syntheses of studies' estimates could enable to appreciate the level of contamination and the comparative importance of animal products as potential sources of Salmonella infections to humans. The objective of this study was to estimate the prevalence of Salmonella in raw animal products of Ethiopia by using meta-analytical methods.

\section{Methods}

The study was conducted according to the guideline of the PRISMA (Preferred Reporting Items for Systematic Reviews and Meta-Analyses) group [13]. The PRISMA check list was used to ensure inclusion of relevant information (see Additional file 1).

\section{Literature search and study selection}

The literature search strategy was described in a previous report [14]. Briefly, published studies were searched in 
Medline, and non-Medline indexed articles were searched in Google scholar and in the lists of references of articles. The last search was done on December 10, 2014. A study was screened for eligibility if (i) it was published in English, (ii) the samples were raw and (iii) collected from slaughter houses, 'super markets' or farms. A study was excluded if (i) the titles and abstracts were not relevant to the outcomes of interest, (ii) it was a duplicate and (iii) the methodology was not appropriate.

\section{Data extraction}

From each eligible study, the first author, year of publication, year of study, location, study design, sample source, sample type, sample size, microbiological methods and numbers of Salmonella positive samples were extracted. The study level estimates and standard errors were derived from the extracted data.

\section{Data analysis}

To produce conservative estimates, a zero reported for the number of positive samples was imputed as 0.5 [15]. The study level estimates were transformed to logit event estimates [16,17] by the following formula: $\operatorname{lp}=\ln [\mathrm{p} /(1-\mathrm{p})]$, where $\mathrm{lp}=$ logit event estimate; $\mathrm{ln}=$ natural $\operatorname{logarithm} ; \mathrm{p}=$ study level estimate. The variances of the estimates were calculated by the following formula: $v(l p)=1 /(n p)+1 /[n$ $(1-p)]$, where $v=$ variance, and $n=$ sample size.

\section{Assessment of bias}

The qualities of the methods (sampling and microbiological) were used to assess the within study biases. The across study bias (small study effects) of the estimates on meat items was visually examined by a funnel plot, and the Egger's regression asymmetry test was used to test the statistical significance of the bias [18]. The Duval and Tweedie non-parametric 'fill and trim' linear random method was used to calculate unbiased estimates [19].

\section{Heterogeneity analysis}

The Galbraith plot was used to get a visual impression of the heterogeneity of the estimates on the prevalence of contaminated meats [20]. The significance of the heterogeneities was assessed by the Cochran's Q test, and a non significant heterogeneity was accepted if the ratio of $\mathrm{Q}$ and the degree of freedom $(\mathrm{Q} / \mathrm{df})$ was less than one. The inverse variance index $\left(\mathrm{I}^{2}\right)$ was used to estimate the percentage of the variation attributable to heterogeneity, and $\mathrm{I}^{2}$ values of $25 \%, 50 \%$ and $75 \%$ were considered as low, moderate and high heterogeneity, respectively [21]. Subgroup analyses were done by sample source (slaughterhouse/market), type of sample (whole muscle/swab) and source species.

\section{Pooled estimates}

The DerSimonian and Laird random effects model was used to pool logit event estimates [22]. The pooled estimates were back transformed to prevalence estimates (p): $\mathrm{p}=\mathrm{e}^{\mathrm{lp}} /\left(\mathrm{e}^{\mathrm{lp}}+1\right)$ : where $\mathrm{e}=$ the base of natural logarithm. Single study omitted influence analyses were done to test the sensitivities of pooled estimates. A study was considered to be influential if the pooled estimate without it was not within the $95 \%$ confidence limits of the overall mean. The $\mathrm{Z}$ test was used to test whether a pooled estimate significantly differs from zero or not. The Chi Square test was used to test the significance of differences in pooled estimates [23,24]. Alpha was set at 0.05 .

Microsoft Office Excel 2007 was used to calculate study level prevalence estimates, logit event estimates, standard errors and to back transform logit event estimates to proportions. Epi info ${ }^{\text {тм }}$ (Version 3.5.1, Center for Disease Control, CDC, USA) was used to compare groups. Stata (Version 11.1, Stata Corp, College Station, Texas) was used in all other analyses.

\section{Results and discussion}

\section{Search and selection of studies}

Figure 1 presents the search results. A total of 165 studies were found, and 128 studies were excluded on the basis of the titles and abstracts. Of the articles screened for eligibility, 15 were excluded due to diverse reasons: two studies were duplicates; one study was serotype specific; the samples were not raw in three studies; in one

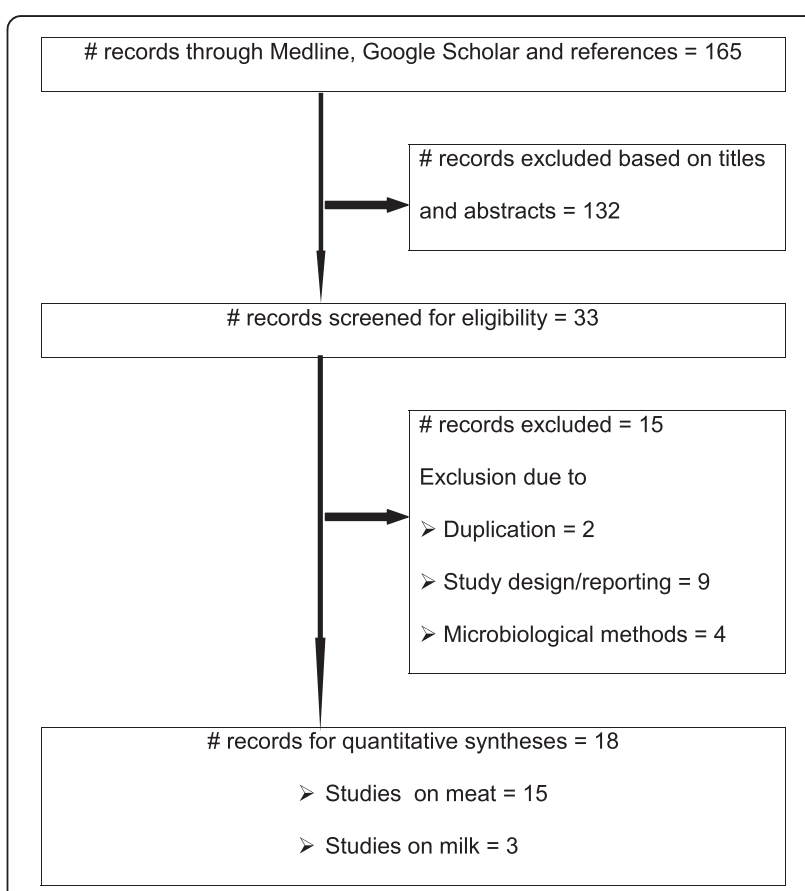

Figure 1 A flow diagram of the selection of eligible studies. 
study, the samples were not neither from abattoirs nor 'super markets' nor farms; the sample sizes were small in two studies; in one study most samples were from a single farm; the exact number of positive samples was not reported in one study, and in four studies the microbiological methods were not appropriate. A total of 18 studies were eligible for quantitative syntheses [25-42].

\section{Characteristics of the eligible studies}

Table 1 presents the characteristics of the eligible studies. The studies were conducted between 1999 and 2011 in Central, Eastern, Northern and Southern Ethiopia. Fifteen studies were on meat samples collected from abattoirs and/or 'supermarkets'. Three studies were on milk samples collected from farms. Data from 3706 meat (beef, pork and mutton, goat, camel and chicken meats) and 395 cow milk samples were considered for quantitative syntheses. The study level estimates ranged from zero in goat meat to $21.01 \%$ in camel meat.

\section{Bias and heterogeneity}

Sampling was random in thirteen studies [25,27-31,33,36, $37,39-42]$. In three studies, samples were taken from all animals presented for slaughter in each sampling day $[26,32,34]$. The sampling methods were not reported in two studies $[35,38]$. The analytical units were $25 \mathrm{~g}$ muscle samples [25,26,29,30,33-39], carcass swabs [27,28,31,32] and one ml milk [40], but not reported in two studies $[41,42]$. In all studies, Salmonella was isolated and identified as per the guideline of the International Organization for Standardization (ISO 6579, 1998-2002) with modifications. Serotypes were reported in 13 studies [25-30,32-38].

Table 1 Characteristics of the eligible studies on Salmonella contaminated products

\begin{tabular}{|c|c|c|c|c|c|c|}
\hline Author & Ys & Location & Sample & Source & $\mathrm{n}$ & Positive (\%) \\
\hline [25] & 1999 & $\mathrm{AA}$ & Beef & Abattoir & 235 & $23(9.79)$ \\
\hline$[26]$ & 1999-2000 & $\mathrm{DZ}$ & Beef & Abattoir & 323 & $9(2.79)$ \\
\hline$[27]^{a}$ & 2005-2006 & $\mathrm{DZ}$ & Beef & Abattoir & 100 & $2(2)$ \\
\hline$[28]^{a}$ & 2006-2007 & $\mathrm{BD}$ & Beef & Abattoir & 186 & $9(4.84)$ \\
\hline [29] & $2002-2003$ & $\mathrm{DZ}$ & Goat meat & Abattoir & 60 & $2(3.33)$ \\
\hline$[30]$ & 2003-2004 & AM & Goat meat & Abattoir & 100 & $0(0)$ \\
\hline$[31]^{a}$ & $2007-2008$ & MD & Goat meat & Abattoir & 60 & $5(8.33)$ \\
\hline [29] & 2002-2003 & $\mathrm{DZ}$ & Mutton & Abattoir & 47 & $5(10.64)$ \\
\hline$[30]$ & 2003-2004 & AM & Mutton & Abattoir & 104 & $2(1.92)$ \\
\hline [31] & 2007-2008 & MD & Mutton & Abattoir & 142 & $20(14.08)$ \\
\hline$[32]^{a}$ & 2004-2005 & AA & Pork & Abattoir & 277 & $11(3.97)$ \\
\hline$[33]^{b}$ & 2004-2005 & AA & Pork & Abattoir & 99 & $2(2.02)$ \\
\hline [34] & 2001-2002 & DJ & Camel meat & Abattoir & 119 & $25(21.01)$ \\
\hline$[35]$ & 2001 & $\mathrm{AA}$ & Chicken meat & Market & 244 & $30(12.30)$ \\
\hline$[36]^{c}$ & 2001-2002 & DA & Chicken meat & Market & 104 & $16(15.38)$ \\
\hline [37] & 2003-2004 & AA & Chicken meat & Market & 208 & $29(13.94)$ \\
\hline$[25]$ & 1999 & AA & Minced beef & Market & 330 & $26(7.88)$ \\
\hline [38] & $2002-2003$ & AA & Minced beef & Market & 160 & $23(14.38)$ \\
\hline [37] & 2003-2004 & AA & Minced beef & Market & 142 & $12(8.45)$ \\
\hline [39] & 2009 & $J M$ & Minced beef & Market & 120 & $1(0.83)$ \\
\hline$[38]$ & $2002-2003$ & $\mathrm{AA}$ & Mutton & Market & 85 & $12(14.12)$ \\
\hline [37] & 2003-2004 & $\mathrm{AA}$ & Mutton & Market & 212 & $23(10.85)$ \\
\hline$[38]$ & $2002-2003$ & AA & Pork & Market & 55 & $9(16.36)$ \\
\hline [37] & 2003-2004 & $\mathrm{AA}$ & Pork & Market & 194 & $22(11.34)$ \\
\hline$[40]$ & 2010 & $\mathrm{AA}$ & Milk & Farm & 195 & $6(3.08)$ \\
\hline$[41]$ & 2010-2011 & $\mathrm{KR}$ & Milk & Farm & 100 & $20(20)$ \\
\hline [42] & $\mathrm{nr}$ & SB & Milk & Farm & 100 & $16(16)$ \\
\hline
\end{tabular}

AA, Addis Ababa; BD, Bahirdar; AM, Addis Ababa and Modjo; DJ, Diredawa and JiJiga; DZ, DebreZeit; JM, Jimma; KR, Kersa; MD, Modjo; n, Sample size; nr, not reported; Ys, year of study; SB, Sebetta; Ys, year of study.

${ }^{a}$ The samples were carcass swabs.

${ }^{\mathrm{b}}$ The samples were mixed abdominal and diaphragmatic muscle samples.

${ }^{\mathrm{C}}$ The samples were taken from a slaughtering plant and markets. 
The funnel plot of the estimates of contaminated meat items was asymmetric (Figure 2) and the intercept of the regression of the standardized effect estimates against the precision significantly deviates from zero [bias coefficient $=-3.23(95 \% \mathrm{CI}=-4.92,-1.53) ; P<0.001]$. The asymmetry of the plot was not due to small study effects, and theoretical missing studies were not incorporated by the Duval and Tweedie method. The plot and tests did not suggest the presence of bias.

Figure 3 presents a forest plot of the logit event estimates of contaminated meat items. Eight estimates were outside the confidence bounds of the regression line of the Galbraith plot (Figure 4), and the variation in prevalence estimates attributable to heterogeneity was substantially high $\left(\mathrm{I}^{2}=76.6 \%\right)$. In a subgroup analysis by sample source, the $\mathrm{I}^{2}$ of the estimates in abattoirs and markets were $82.9 \%$ and $47.1 \%$ respectively. In a subgroup analysis by source species, the $\mathrm{I}^{2}$ was moderate to high in beef, goat meat and mutton from abattoirs and in minced beef from markets (Table 2). In a subgroup analysis of abattoir data, the $\mathrm{I}^{2}$ values were $85.9 \%$ for muscle and $78.9 \%$ for swab samples, but the pooled estimates (5.98\% swab, vs. $5.05 \%$ muscle) did not differ significantly $(P>0.05)$. On the whole, differences in the meat handling practice, and the hygienic standards in slaughterhouses, and the transport means, the meat handling practice and storage facilities in the markets could have contributed to the heterogeneity of the study level estimates. The between studies variation in milk studies could have been due to differences in the occurrence of Salmonella among the study populations. In all instances, several factors including the breed, origin, and management of animals, and prior exposure of slaughtered animals to stress might have contributed to the within and between group variations.

\section{Pooled estimates}

Table 2 presents pooled estimates of Salmonella in animal products. The pooled prevalence estimates of contaminated pork, goat meat, beef and mutton carcasses in slaughter houses were $3.57 \%, 3.86 \%, 4.53 \%$ and $8.02 \%$, respectively. The pooled estimates of contaminated minced beef, mutton, pork and chicken meat collected from markets were $8.34 \%, 11.86 \%, 12.59 \%$ and $13.53 \%$ respectively, and that of raw milk was $10.76 \%$. All single study omitted estimates were within the $95 \%$ confidence bounds of the respective means. The source species significantly affected the occurrence of Salmonella in samples taken from slaughter houses $\left(\mathrm{X}^{2}=8.57 ; \mathrm{df}=3 ; P<0.05\right)$ but not in samples collected from markets $\left(\mathrm{X}^{2}=7.11 ; \mathrm{df}=3 ; P>0.05\right)$.

Although carcasses from apparently healthy animals are generally assumed to be free of Salmonella, contamination occurs in slaughter houses. The disparities in the extents of contamination could be due to differences in the skills of personnel in gut evisceration, carcass examination, carcass handling, and the hygienic standards of the slaughter houses, and there have been reports on the substandard knowledge, attitude and practice (KAP) of slaughterhouse personnel on food safety in Ethiopia $[43,44]$. Therefore, given the substandard KAP of personnel and the insanitary slaughterhouses' environment in most cases in point, and a Salmonella carrier prevalence of $7.07 \%$ in cattle to $43.81 \%$ in pigs [12], the likelihood of carcass contamination could be considerable. The differences in the prevalence of Salmonella by meat type could be ascribed to differences in the occurrence of the bacteria

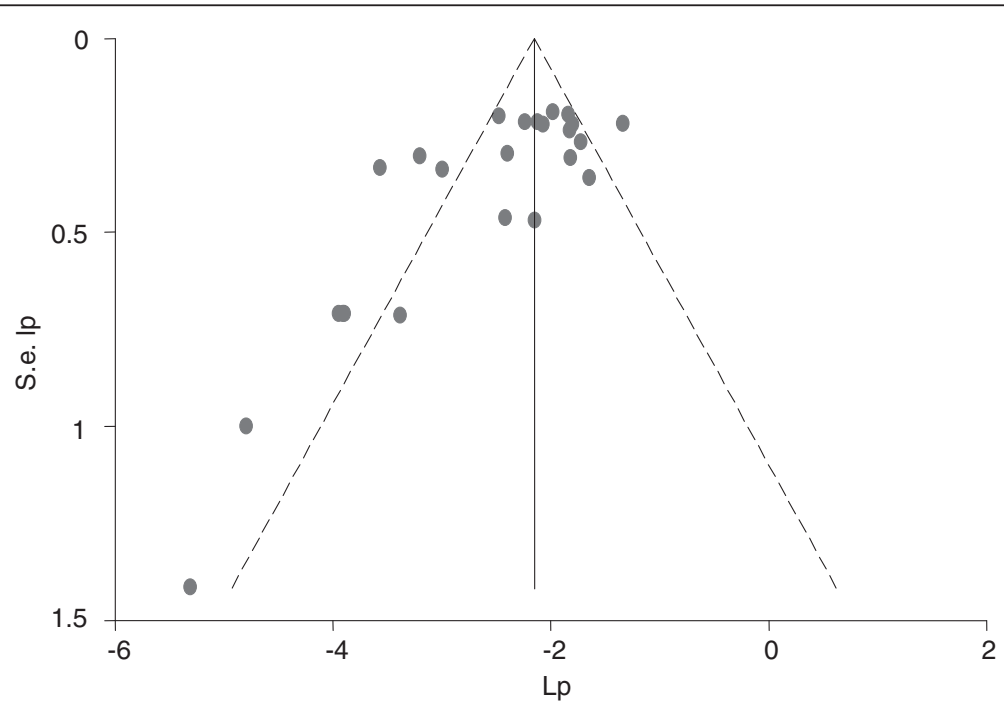

Figure 2 Funnel plot of the logit event estimates (Ip) of Salmonella in meat items. 


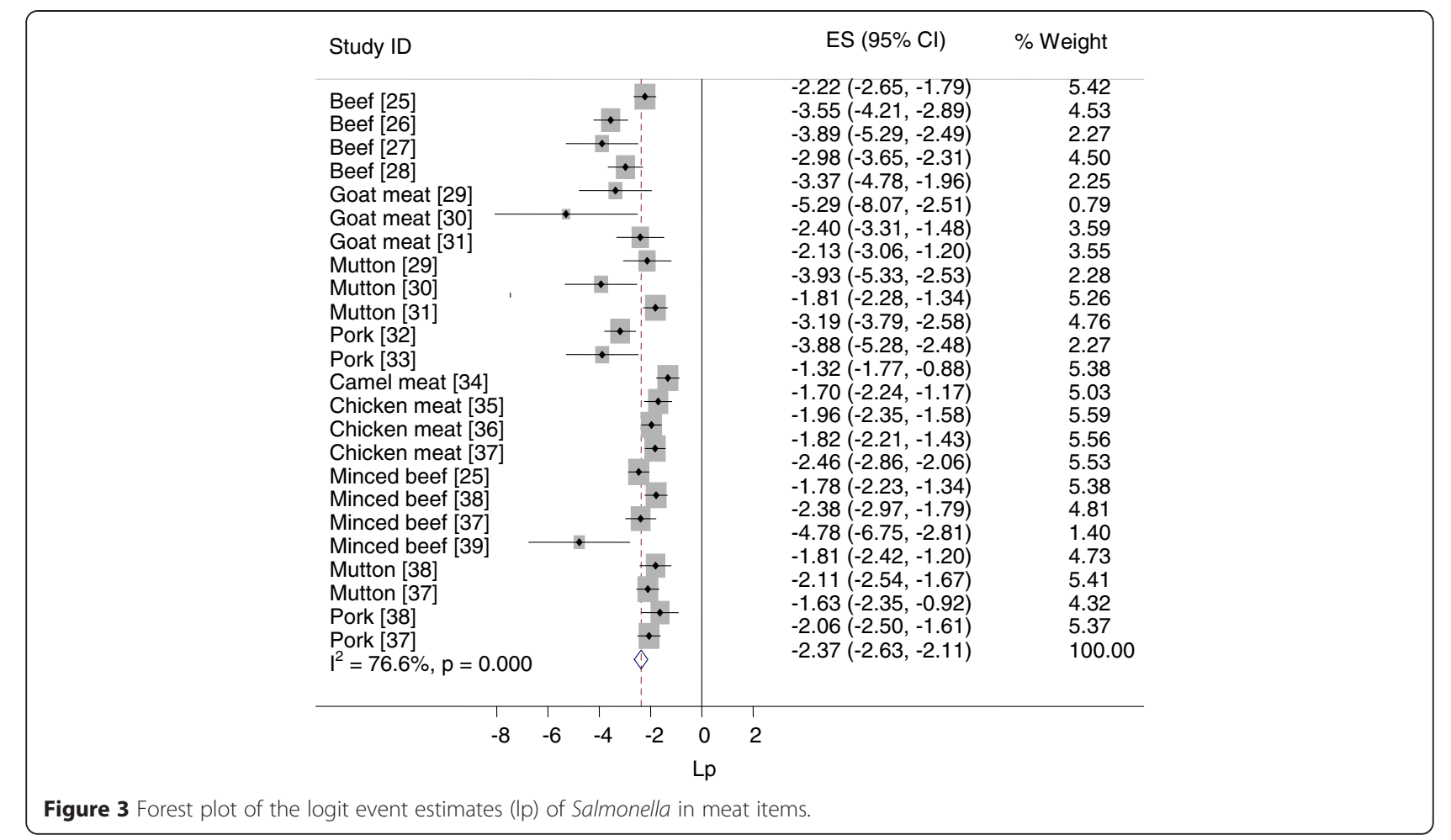

by source species that apparently influences the levels of contamination of slaughterhouses, personnel and slaughtering equipments. However, notwithstanding the effect of the source species, the lower prevalence of contaminated pork compared to other meat items could have been due to the hot water treatment of pig carcasses.

The odds of contaminated meat was more than twice higher in markets than in slaughterhouses $\left[X^{2}=43.54\right.$; $P=0.001 ; \mathrm{OR}=2.25(95 \% \mathrm{CI}=1.75,2.89)]$, and this could be due to further exposure of meat items to additional sources of contamination outside the slaughterhouses,

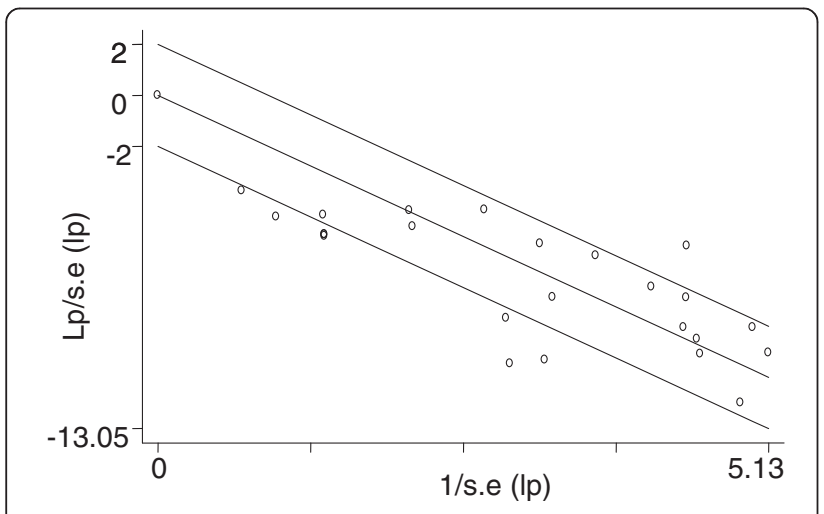

Lp, logit event estimate; o, b/s.e (b); - - Fitted values

Figure 4 Galbraith plot of the logit event estimates (Ip) of Salmonella in meat items. and bacterial multiplication in faulty storages. The loading and unloading practice, the meat handling and processing practice, lack of adequate product holding facilities and power interruption could be implicated as potential factors that might have contributed to the higher prevalence of contaminated meat items in the markets. Moreover, in butcheries, carcasses are left in the open and exposed to environmental contaminants; the same utensils (cutting board and knives) are used for edible offal (tongue and rumen) and meats, and higher levels of contamination have been recorded in meat samples collected from retail markets, bars, restaurants and streets [45-47]. Furthermore, a higher bacterial count in retail outlets than in slaughterhouses [48], a positive association of bacterial count with market display temperature [49], and a linear association of temperature and cases of human salmonellosis [50] have been recorded elsewhere.

Beef, goat meat and milk are often consumed raw or undercooked and appear to be main vehicles of Salmonella to humans in Ethiopia. Consumption of raw mutton is less common, and pork is not popular due to either religious or cultural taboos or both. Chicken meat could be a potential source of contamination to other meat items with a greater risk during festive occasions where preparation of varieties of meat dishes (raw or undercooked and cooked) is a common practice in several households. In contrast, source attribution studies in Europe, USA, New Zealand and Japan attributed pigs for 10 to $23 \%$ [51], broilers for $48 \%$ [52], pigs for $60 \%$ [53] 
Table 2 Pooled prevalence of Salmonella in raw meat and milk

\begin{tabular}{|c|c|c|c|c|c|c|c|}
\hline \multirow[t]{2}{*}{ Source } & \multirow[t]{2}{*}{ Product } & \multicolumn{2}{|l|}{ Pooled estimate } & \multicolumn{4}{|c|}{ Heterogeneity } \\
\hline & & $\mathrm{p}(95 \% \mathrm{Cl})$ & Z-p & $\bar{Q}$ & Q-p & $\mathrm{Q} / \mathrm{df}$ & $1^{2}$ \\
\hline \multirow[t]{6}{*}{ Abattoir } & Overall & $5.57(3.39,9.01)$ & 0.000 & 70.09 & 0.000 & 5.91 & 82.9 \\
\hline & Pork & $3.57(2.09,6.06)$ & 0.000 & 0.80 & 0.371 & 0.80 & 0.0 \\
\hline & Goat meat & $3.86(1.08,23.20)$ & 0.000 & 4.42 & 0.110 & 2.21 & 54.8 \\
\hline & Beef & $4.53(2.17,9.25)$ & 0.000 & 14.44 & 0.002 & 4.81 & 79.2 \\
\hline & Mutton & $8.02(3.04,19.51)$ & 0.000 & 7.98 & 0.019 & 3.99 & 74.9 \\
\hline & Camel $^{\dagger}$ & $21.02(14.62,29.26)$ & 0.000 & & & & \\
\hline \multirow[t]{5}{*}{ Market } & Overall & $11.72(9.71,14.08)$ & 0.000 & 18.91 & 0.041 & 1.89 & 47.1 \\
\hline & Minced beef & $8.34(4.75,14.22)$ & 0.000 & 11.85 & 0.008 & 3.95 & 74.7 \\
\hline & Mutton & $11.86(8.64,16.07)$ & 0.000 & 0.62 & 0.431 & 0.62 & 0.0 \\
\hline & Pork & $12.59(8.99,17.35)$ & 0.000 & 0.98 & 0.322 & 0.98 & 0.0 \\
\hline & Chicken & $13.53(10.93,16.64)$ & 0.000 & 0.65 & 0.721 & 0.33 & 0.0 \\
\hline Farm & Milk & $10.76(4.03,25.71)$ & 0.000 & 18.81 & 0.001 & 9.41 & 89.4 \\
\hline
\end{tabular}

and layers for more than 50\% [54] of the human illnesses, respectively.

\section{Serotypes}

S. Dublin (28.57\%), S. Infantis (45.95\%) and S. Saintpaul $(40 \%)$ were the most frequent serotypes isolated from beef, small ruminant and camel meat, respectively (Table 3). In pork and chicken meat, S. Newport (34.21\%) and $S$. Braenderup (36\%), respectively, were the most frequent isolates (Table 4). Although the preponderance of the serovars by meat type differ from reports elsewhere [55] and could vary across time [56], most have been isolated from samples taken from humans in Ethiopia: $S$. Braenderup, S. Newport, S. Dublin, S. Infantis, S. Saintpaul

Table 3 Number (\%) of serotypes isolated from ruminant meat

\begin{tabular}{llll}
\hline Isolates & Serotypes & Total & Author \\
\hline Beef $(n=91)^{a}$ & S. Dublin & $26(28.57)$ & {$[25,26,37,38]$} \\
& S. Anatum & $20(21.98)$ & {$[25,26,37,38]$} \\
& S. Saintpaul & $11(12.09)$ & {$[25,37,38]$} \\
& S. Newport & $6(6.59)$ & {$[27,28,37]$} \\
& S. Typhimurium & $5(5.50)$ & {$[26-28,37]$} \\
& S. Mishmarhaemek & $5(5.50)$ & {$[26]$} \\
Mutton/goat $(n=37)^{b}$ & S. Infantis & $17(45.95)$ & {$[29,37,38]$} \\
& S. Newport & $12(32.43)$ & {$[37]$} \\
& S. Typhimurium & $4(10.81)$ & {$[30,37]$} \\
Camel $(n=25)^{b}$ & S. Saintpaul & $10(40)$ & {$[34]$} \\
& S. Braenderup & $8(32)$ & {$[34]$} \\
& S. Muenchen & $3(12)$ & {$[34]$} \\
\hline
\end{tabular}

${ }^{a}$ Serotypes that accounted for $5 \%$ or more of the total isolates. ${ }^{\mathrm{b}}$ Serotypes that accounted for $10 \%$ or more of the total isolates. and S. Typhimurium from clinical samples [57,58], and $S$. Anatum, $S$. Newport and $S$. Dublin from personnel working in markets/abattoirs [25,37]. Therefore, despite limited data on isolates of human origin [14], and the absence of source attribution studies to human illnesses, the relative occurrence of the serovars implies their importance as potential causes of food-borne salmonellosis in Ethiopia.

Of the market isolates, resistance to three or more antimicrobials (multi-drug resistance, MDR) was recorded in S. Braenderup [35,37,59,60], S. Newport, S. Haifa [37], $S$. Anatum [35,57], S. Saintpaul, S. Roughform, S. Uganda [59] and $S$. Typhimurium [59-61]. Moreover, more than half of the milk isolates (25/42), [40-42], and 19.12\% of the isolates of slaughtered ruminant origin were MDR, and certain strains were reportedly resistant to drugs uncommonly used in the veterinary sector [62]. Furthermore, Salmonella has been isolated from personnel in contact with

Table 4 Number (\%) of serotypes isolated from non-ruminant meat

\begin{tabular}{llll}
\hline Isolates & Serotypes & Total & Author \\
\hline Chicken $(n=75)^{\text {a }}$ & S. Braenderup & $27(36)$ & {$[35-37]$} \\
& S. Anatum & $9(12)$ & {$[35-37]$} \\
& S. Hadar & $8(10.67)$ & {$[36,37]$} \\
& S. Typhimurium & $6(8)$ & {$[35-37]$} \\
& S. Uganda & $5(6.67)$ & {$[35]$} \\
& S. Newport & $4(5.33)$ & {$[37]$} \\
Pork $(n=38)^{b}$ & S. Saintpaul & $4(5.33)$ & {$[35]$} \\
& S. Newport & $13(34.21)$ & {$[33,37]$} \\
& S. Haifa & $5(13.16)$ & {$[37]$} \\
\hline
\end{tabular}

${ }^{a}$ Serotypes that accounted for $5 \%$ or more of the isolates.

${ }^{b}$ Serotypes that accounted for $10 \%$ or more of the isolates. 
animals or animal products [14], and the proportion of MDR isolates of human origin was estimated at $79.56 \%$ [63]. In general, regardless of the limited data on the drug resistance profiles of Salmonellae isolated from animal products, the risk of acquiring MDR Salmonella through the consumption of raw or undercooked animal products appears considerable.

\section{Implications and limitations}

The pooled estimates demonstrate the level of contaminated animal products meant for public consumption and imply the need for strict observations of food safety in slaughterhouses and markets. Policy makers could make use of the estimates as inputs to enforce food safety measures and reduce the risks of contamination of animal products. The limited number of studies was the main constraint to calculate robust pooled estimates by sample source and type. Therefore, as most studies have been carried out in slaughterhouses and markets in Addis Ababa and the surrounding towns, the pooled prevalence estimates of contaminated meat items are more appropriate to bigger urban than to rural and smaller settings of the country.

\section{Conclusions}

The estimates demonstrate the extent of contamination, and entail the need for quality assurance programs to ensure the safety of animal products to consumers. Food safety educational programs in slaughterhouses and markets, and public education as regards the risks of consumption of raw or undercooked animal products are important lines of defense against Salmonella and other food-borne pathogens.

\section{Additional file}

Additional file 1: PRISMA checklist.

\section{Competing interests}

The authors declare that they have no competing interests.

\section{Authors' contributions}

TG conceived the study design, searched the literature, extracted and analyzed the data, interpreted the results and drafted the manuscript. EZG revised the manuscript. The authors have read and approved the manuscript.

\section{Acknowledgements}

We thank Dr. Bayleyegne Molla, Dr. Sefinew Alemu and Mr. Bayeh Abera for providing us with their articles, and Dr. Tesfaye Sisay for his help in literature search.

\section{Author details}

'Department of Biomedical Sciences, College of Veterinary Medicine and Agriculture, Addis Ababa University, P.O. Box 34, Debre Zeit, Ethiopia. 2Department of Veterinary Laboratory Technology, Faculty of Agriculture and Veterinary Science, Ambo University, P.O. Box 19, Ambo, Ethiopia.
Received: 30 December 2014 Accepted: 15 April 2015

Published online: 21 April 2015

\section{References}

1. Senthikumar B, Prabakaran G. Multi drug resistant Salmonella Typhi in Asymptomatic Typhoid carriers among food handlers in Namakkal District, Tamil Nadu. Indian J Med Microbiol. 2005;23:92-4.

2. Wong DMALF, Hald T, Wolf PJVD, Swanenburg M. Epidemiology and control measures for Salmonella in pigs and pork. Livest Prod Sci. 2002;76:215-22.

3. Bolton DJ, Meally A, McDowell D, Blair IS. A survey for serotyping, antibiotic resistance profiling and PFGE characterization of and the potential multiplication of restaurant Salmonella isolates. J Appl Microbiol. 2007;103:1681-90.

4. Kinross P, van Alphen L, Urtaza MJ, Struelens M, Takkinen J, Coulombier D, et al. Multidisciplinary investigation of a multicountry outbreak of Salmonella Stanley infections associated with turkey meat in the European Union, August 2011 to January 2013. Euro Surveill. 2014, 19.

5. Haeghebaert S, Duche L, Gilles C, Masini B, Dubreuil M, Minet JC, et al. Minced beef and human salmonellosis: review of the investigation of three outbreaks in France. Euro Surveill. 2001;6:21-6.

6. Kivi M, Hofhuis A, Notermans DW, Wannet WJ, Heck ME, Van De Glessen AW, et al. A beef-associated outbreak of Salmonella Typhimurium DT104 in The Netherlands with implications for national and international policy. Epidemiol Infect. 2007;135:890-9.

7. Luzzi I, Galetta P, Massari M, Rizzo C, Dionisi AM, Filetici E, et al. An Easter outbreak of Salmonella Typhimurium DT 104A associated with traditional pork salami in Italy. Euro Surveill. 2007;12:E11-2.

8. Jansen A, Frank C, Stark K. Pork and pork products as a source for human salmonellosis in Germany. Berl Munch Tierarztl Wochenschr. 2007;120:340-6.

9. Gould LH, Mungai E, Behravesh CB. Outbreaks attributed to cheese: differences between outbreaks caused by unpasteurized and pasteurized dairy products, United States, 1998-2011. Foodborne Pathog Dis. 2014;11:545-51.

10. Pires SM, Evers EG, van Pelt W, Ayers T, Scallan E, Angulo FJ, et al. Attributing the human disease burden of foodborne infections to specific sources. Foodborne Pathog Dis. 2009;6:417-24.

11. Kuchenmüller T, Hird S, Stein C, Kramarz P, Nanda A, Havelaar AH. Estimating the global burden of foodborne diseases - a collaborative effort. Euro Surveill. 2009;14:1-4.

12. Tadesse G, Tessema TS. A meta-analysis of the prevalence of Salmonella in food animals in Ethiopia. BMC Microbiol. 2014. doi:10.1186/s12866-014-0270-y.

13. Moher D, Liberati A, Tetzlaff J, Altman DG, The PRISMA Group. Preferred reporting items for systematic reviews and meta-analyses: the PRISMA statement. PLoS Med. 2009. doi:10.1371/journal.pmed.1000097.

14. Tadesse G. Prevalence of human salmonellosis in Ethiopia: a systematic review and meta-analysis. BMC Infect Dis. 2014. doi:10.1186/1471-2334-14-88.

15. Tricco AC, Ng CH, Gilca V, Anonychuk A, Pham B, Berliner S. Canadian oncogenic human papillomavirus cervical infection prevalence: systematic review and meta-analysis. BMC Infect Dis. 2011. doi:10.1186/1471-2334-11-235.

16. Calvo-Muñoz I, Gómez-Conesa A, Sánchez-Meca J. Prevalence of low back pain in children and adolescents: a meta-analysis. BMC Pediatr. 2013. doi:10.1186/1471-2431-13-14.

17. Hurley JC. Lack of impact of selective digestive decontamination on pseudomonas aeruginosa ventilator associated pneumonia: benchmarking the evidence base. J Antimicrob Chemother. 2011;66:1365-73.

18. Egger M, Davey Smith G, Schneider M, Minder C. Bias in meta-analysis detected by a simple graphical test. BMJ. 1997;315:629-34.

19. Duval S, Tweedie R. Trim and fill: a simple funnel-plot-based method of testing and adjusting for publication bias in meta-analysis. Biometrics. 2000;56:455-63.

20. Galbraith RF. A note on graphical presentation of estimated odds ratios from several clinical trials. Stat Med. 1988;7:889-94.

21. Higgins JP, Thompson SG. Quantifying heterogeneity in a meta-analysis. Stat Med. 2002;21:1539-58.

22. DerSimonian R, Laird N. Meta-analysis in clinical trials. Control Clin Trials. 1986;7:177-88

23. Yang Y, Li X, Zhou F, Jin Q, Gao L. Prevalence of drug-resistant tuberculosis in Mainland China: systematic review and meta-analysis. PLOS ONE. 2011. doi:10.1371/journal.pone.0020343.

24. Gao L, Zhang L, Jin Q. Meta-analysis: prevalence of HIV infection and syphilis among MSM in China. Sex Transm Infect. 2009. doi:10.1136/sti.2008.034702. 
25. Nyeleti C, Molla B, Hildebrandt G, Kleer J. The prevalence and distribution of Salmonellae in slaughter cattle, slaughterhouse personnel and minced beef in Addis Ababa (Ethiopia). Bull Anim HIth Prod Afr. 2000;48:19-24.

26. Alemayehu D, Molla B, Muckle A. Prevalence and antimicrobial resistance pattern of Salmonella isolates from apparently healthy slaughtered cattle in Ethiopia. Trop Anim Health Prod. 2003;35:309-19.

27. Sibhat B, Zewde BM, Zerihun A, Muckle A, Cole L, Boerlin P, et al. Salmonella serovars and antimicrobial resistance profiles in beef cattle, slaughterhouse personnel and slaughterhouse environment in Ethiopia. Zoonoses Public HIth. 2011:58:102-9.

28. Alemu S, Zewde BM. Prevalence and antimicrobial resistance profiles of Salmonella enterica serovars isolated from slaughtered cattle in Bahir Dar, Ethiopia. Trop Anim Health Prod. 2012;44:595-600.

29. Woldemariam E, Molla B, Alemayehu D, Muckle A. Prevalence and distribution of Salmonella in apparently healthy slaughtered sheep and goats in Debre Zeit, Ethiopia. Small Rumin Res. 2005;58:19-24.

30. Molla W, Molla B, Alemayehu D, Muckle A, Cole L, Wilkie E. Occurrence and antimicrobial resistance of Salmonella serovars in apparently healthy slaughtered sheep and goats of central Ethiopia. Trop Anim Health Prod. 2006:38:455-62.

31. Teklu A, Negussie H. Assessment of risk factors and prevalence of Salmonella in small ruminants and environment in an export abattoir, Modjo, Ethiopia. Am-Eurasian J Agric Environ Sci. 2011;10:992-9.

32. Aragaw K, Molla B, Muckle A, Cole L, Wilkie E, Poppe C, et al. The characterization of Salmonella serovars isolated from apparently healthy slaughtered pigs at Addis Ababa abattoir, Ethiopia. Prev Vet Med. 2007;82:252-61.

33. Molla B, Berhanu A, Muckle A, Cole L, Wilkie E, Kleer J, et al. Multidrug resistance and distribution of Salmonella serovars in slaughtered pigs. J Vet Med B Infect Dis Vet Public Health. 2006:53:28-33.

34. Molla B, Mohammed A, Salah W. Salmonella prevalence and distribution of serotypes in apparently healthy slaughtered camels (Camelus dromedarius) in eastern Ethiopia. Trop Anim Health Prod. 2004;36:451-8.

35. Tibaijuka B, Molla B, Hildebrandt G, Kleer J, Salah W. Occurrence of Salmonellae in retail raw chicken products in Ethiopia. Berl Münch Tierärztl Wschr. 2003;116:55-8.

36. Molla B, Mesfin A. A survey of Salmonella contamination in chicken carcass and giblets in central Ethiopia. Rev Méd Vét. 2003;154:267-70.

37. Zewdu E, Poppe C. Antimicrobial resistance pattern of Salmonella serotypes isolated from food items and personnel in Addis Ababa, Ethiopia. Trop Anim Health Prod. 2009:41:241-9.

38. Ejeta G, Molla B, Alemayehu D, Muckle A. Salmonella serotypes isolated from minced meat beef, mutton and pork in Addis Ababa, Ethiopia. Rev Méd Vét. 2004;155:547-51.

39. Tassew H, Abdissa A, Beyene G, Gebre-selassie S. Microbial flora and food borne pathogens on minced meat and their susceptibility to antimicrobial agents. Ethiop J Health Sci. 2010;20:137-43.

40. Addis Z, Kebede N, Worku Z, Gezahegn H, Yirsaw A, Kassa T. Prevalence and antimicrobial resistance of Salmonella isolated from lactating cows and in contact humans in dairy farms of Addis Ababa: a cross sectional study. BMC Infect Dis. 2011. doi: 10.1186/1471-2334-11-222.

41. Tadesse T, Dabassa A. Prevalence and antimicrobial resistance of Salmonella isolated from raw milk samples collected from Kersa District, Jimma Zone, South West Ethiopia. J Med Sci. 2012;12:224-8.

42. Abate AA, Rakshit SK, Anal AK. Genotypic and phenotypic characterization of antimicrobial resistance patterns of Salmonella strains isolated from raw milk in Sebeta, Ethiopia. Int J Adv Lif Sci. 2013;6:192-9.

43. Ferede B. Isolation and identification of Salmonella, antimicrobial sensitivity and assessment of public awareness on the management of raw goat meat slaughtered at Diredawa municipal abattior. Eastern Ethiopia: MSc thesis. Addis Ababa University, Microbiology, Immunology and Veterinary Public Health department; 2014

44. Hailesellasie M, Tadele H, Adhana K, Kalayou S. Food safety knowledge and practices of abattoir and butchery shops and the microbial profile of meat in Mekelle City, Ethiopia. Asian Pac J Trop Biomed. 2013;3:407-12.

45. Muleta D, Ashenafi M. Salmonella and Shigella and growth potential of other food-borne pathogens in Ethiopian street-vended foods. East Afr Med J. 2001;78:576-80.

46. Molla B, Kleer J, Sinell H. Occurrence, distribution and level of Salmonella in selected food items in Addis Ababa (Ethiopia). Fleischwirtschaft Int. 1999:4:37-9.
47. Tegegne M, Ashenafi M. Microbial load and incidence of Salmonella species in 'Kitfo' a traditional Ethiopian spiced minced meat dish. Ethiop J health Dev. 1998;12:135-40

48. Vaidya VM, Paturkar AM, Waskar VS, Zende RJ, DUBAL ZB. Comparison of pathogenic microorganisms on poultry carcasses in organized slaughterhouses and retail outlets in and around Mumbai city. J Muscle Foods. 2010;21:197-209.

49. Arroyo G, Arroyo JA. Detection of Salmonella serotypes from edible organ meats in Madrid, Spain. Food Microbiol. 1995;12:13-30.

50. Kovats RS, Edwards SJ, Hajat S, Armstrong BG, Ebi KL, Menne B. The effect of temperature on food poisoning: a time-series analysis of salmonellosis in ten European countries. Epidemiol Infect. 2004;132:443-53.

51. Mainar-Jaime RC, Atashparvar N, Chirino-Trejo M, Rahn K. Survey on Salmonella prevalence in slaughter pigs from Saskatchewan. Can Vet J. 2008;49:793-6.

52. Guo C, Hoekstra RB, Schroeder CM, Pires SM, Ong KL, Hartnett E, et al. Application of Bayesian techniques to model the burden of human salmonellosis attributable to US food commodities at the point of processing: adaptation of a Danish model. Foodborne Pathog Dis. 2011;8:509-16.

53. Mullner P, Jones G, Noble A, Spencer SE, Hathaway S, French NP. Source attribution of food-borne zoonoses in New Zealand: a modified Hald model. Risk Anal. 2009;29:970-84.

54. Toyofuku H, Pires SM, Hald T. Salmonella source attribution in Japan by a microbiological subtyping approach. EcoHealth. 2011;7 Suppl 1:22-3.

55. Pui CF, Wong WC, Chai LC, Tunung R, Jeyaletchumi P, Hidayah MSN, et al. Salmonella: a food borne pathogen. Int Food Res J. 2011;18:465-73.

56. Galanis E, Lo Fo Wong DM, Patrick ME, Binsztein N, Cieslik A, Chalermchikit T, et al. Web-based surveillance and global Salmonella distribution, 2000-2002. Emerg Infect Dis. 2006;12:381-8.

57. GebreYohannes A. Salmonella from Ethiopia: prevalent species and their susceptibility to drugs. Ethiop Med J. 1985;23:97-102.

58. Beyene G, Nair S, Asrat D, Mengistu Y, Engers H, Wain J. Multidrug resistant Salmonella Concord is a major cause of salmonellosis in children in Ethiopia. J Infect Dev Ctries. 2011;5:23-33.

59. Molla B, Mesfin A, Alemayehu D. Multiple antimicrobial-resistant Salmonella serotypes isolated from chicken carcass and giblets in Debre Zeit and Addis Ababa, Ethiopia. Ethiop J Health Dev. 2003;17:131-49.

60. Molla B, Salah W, Alemayehu D, Mohammed A. Antimicrobial resistance pattern of Salmonella serotypes isolated from apparently healthy slaughtered camels (Camelus dromedarius) in eastern Ethiopia. Berl Müunch Tierärztl Wschr. 2004;117:39-45.

61. Molla B, Kleer J, Sinell HJ. Antibiotic resistance pattern of foodborne Salmonella isolates in Addis Ababa (Ethiopia). Berl Müunch Tierärztl Wschr. 1999:112:41-3.

62. Tadesse G. A meta-analysis of the proportion of animal Salmonella isolates resistant to drugs used against human salmonellosis in Ethiopia. BMC Infect Dis. 2015. doi 10.1186/s12879-015-0835-x.

63. Tadesse G. A meta-analysis of the proportion of antimicrobial resistant human Salmonella isolates in Ethiopia. BMC Pharmacol Toxicol. 2014. doi:10.1186/2050-6511-15-51 619.

\section{Submit your next manuscript to BioMed Central and take full advantage of:}

- Convenient online submission

- Thorough peer review

- No space constraints or color figure charges

- Immediate publication on acceptance

- Inclusion in PubMed, CAS, Scopus and Google Scholar

- Research which is freely available for redistribution

Submit your manuscript at www.biomedcentral.com/submit 